\title{
A COMPARISON OF KELLER'S ARTHROPLASTY AND DISTAL METATARSAL OSTEOTOMY IN THE TREATMENT OF ADULT HALLUX VALGUS
}

\author{
TIMOTHY TURNBULL, WILLIAM GRANGE
}

\author{
From the North East Thames Regional Orthopaedic Centre, Black Notley Hospital, Braintree
}

\begin{abstract}
A prospective trial is reported which compares distal osteotomy of the first metatarsal with Keller's arthroplasty in the treatment of adult hallux valgus. A total of 33 patients attended for review at least three years after operation. Symptomatic improvement, as assessed by patient satisfaction, pain relief, cosmetic improvement and restoration of function, was similar in the two groups. Objective measurement showed that the range of movement of the metatarsophalangeal joint was better maintained after osteotomy, as was the relationship of the sesamoid bones to the head of the first metatarsal. Correction of the valgus deformity also was significantly better in the patients who underwent osteotomy and in these patients the first intermetatarsal angle was reduced to within normal limits. There was no evidence that initial degenerative changes or subluxation at the metatarsophalangeal joint compromised a successful result from osteotomy.
\end{abstract}

Pedobarograph studies have demonstrated that patients with hallux valgus have an abnormal pattern of forefoot loading. Keller's procedure so defunctions the great toe in these patients as to cause even more imbalance of load distribution (Dhanendran, Pollard and Hutton 1980). Restoration of mechanical function would therefore seem more likely to be achieved by operative techniques other than excision arthroplasty.

Distal osteotomy of the first metatarsal is well documented as being a reliable method of treating hallux valgus in adolescents and young adults. Blunden (1968) and Glynn, Dunlop and FitzPatrick (1980) used the Peabody-Mitchell modification of Hohmann's osteotomy (Hawkins. Mitchell and Hedrick 1945; Mitchell et al. 1958). Mygind (1952) and Gibson and Piggott (1962) reported on Thomasen's adaptation of this osteotomy and Wilson (1963) described his oblique displacement osteotomy.

The situation in the older patient, however, remains less well defined. Symptomatic improvement in the middle-aged and elderly has been achieved by osteotomy (Hawkins et al. 1945), although careful patient selection is very important (Miller 1974). A stiff metatarsophalangeal joint has been the reported outcome when osteotomy has been undertaken in the presence of subluxation (Bonney and Macnab 1952) or osteoarthritis (Hawkins et al. 1945). If these are to be considered as relative

T. J. Turnbull, FRCS, Senior Registrar in Orthopaedic Surgery W. J. Grange, MA, FRCS. Consultant Orthopaedic Surgeon The London Hospital, Whitechapel, London E1 1 BB, England. Requests for reprints should be sent to $\mathrm{Mr} \mathrm{W}$. J. Grange.

( 1986 British Editorial Society of Bone and Joint Surgery $0301620 \mathrm{X} / 86 / 1051 \$ 2.00$ contra-indications to osteotomy (Cholmeley 1958; Gibson and Piggott 1962), then many patients are precluded from undergoing more conservative surgery than joint excision.

A prospective trial was undertaken to determine more clearly the role of metatarsal osteotomy in the treatment of patients over the age of 30 years with symptomatic hallux valgus.

Table I. Clinical details at the time of operation

\begin{tabular}{lcc} 
& $\begin{array}{c}\text { Excision } \\
\text { arthroplasty }\end{array}$ & $\begin{array}{c}\text { Metatarsal } \\
\text { osteotomy }\end{array}$ \\
Average age (years) & $60(3770)$ & $55(32-79)$ \\
Average duration of symptoms (years) & 7 & 10 \\
Presenting complaint & & \\
$\quad \begin{array}{l}\text { Pain (\%) } \\
\quad \text { Deformity (\%) }\end{array}$ & 100 & 100 \\
$\quad$ Footwear (\%) & 60 & 62 \\
Restricted walking (\%) & 85 & 83 \\
Family history (\%) & 86 & 87 \\
Women (\%) & 35 & 53 \\
\hline
\end{tabular}

Figures in brackets are ranges

\section{MATERIAL AND METHODS}

In a controlled trial 33 patients over the age of 30 years, admitted to hospital for operative correction of symptomatic hallux valgus, underwent either excision arthroplasty or metatarsal osteotomy. A detailed record sheet was completed for each patient and particular attention was paid to accurate localisation of the forefoot pain. The choice of operation depended upon whether the patient's hospital record number was odd or even. 
Table II. Radiological assessment of the metatarsophalangeal joint

\begin{tabular}{|c|c|c|c|c|}
\hline & \multicolumn{2}{|c|}{ Before operation } & \multicolumn{2}{|c|}{ Three years after operation } \\
\hline & $\begin{array}{l}\text { Excision } \\
\text { arthroplasty }\end{array}$ & $\begin{array}{l}\text { Metatarsal } \\
\text { osteotomy }\end{array}$ & $\begin{array}{l}\text { Excision } \\
\text { arthroplasty }\end{array}$ & $\begin{array}{l}\text { Metatarsal } \\
\text { osteotomy }\end{array}$ \\
\hline Valgus angle (degrees) & 36 & 38 & 21 & 12 \\
\hline Subluxation (\%) & 69 & 89 & $\mathrm{n} / \mathbf{a}$ & 0 \\
\hline Osteoarthritis. (\%) & 81 & 74 & $\mathrm{n} / \mathbf{a}$ & 58 \\
\hline First intermetatarsal angle (degrees) & 13 & 16 & 12 & 7 \\
\hline
\end{tabular}

n a, not applicable

Table III. Range of movement, in degrees, at the first metatarsophalangeal joint

\begin{tabular}{|c|c|c|c|c|}
\hline & \multicolumn{2}{|c|}{ Before operation } & \multicolumn{2}{|c|}{ Three years after operation } \\
\hline & $\begin{array}{l}\text { Excision } \\
\text { arthroplasty }\end{array}$ & $\begin{array}{l}\text { Metatarsal } \\
\text { osteotomy }\end{array}$ & $\begin{array}{l}\text { Excision } \\
\text { arthroplasty }\end{array}$ & $\begin{array}{l}\text { Metatarsal } \\
\text { osteotomy }\end{array}$ \\
\hline Active dorsiflexion & 24 & 30 & 35 & 49 \\
\hline Passive dorsiflexion & 42 & 46 & 38 & 50 \\
\hline Active plantarflexion & 9 & 12 & -3 & 5 \\
\hline Passive plantarflexion & 16 & 19 & 6 & 14 \\
\hline
\end{tabular}

Table IV. Rotation of the hallux and the variation in valgus deformity

\begin{tabular}{|c|c|c|c|c|}
\hline & \multicolumn{2}{|c|}{ Before operation } & \multicolumn{2}{|c|}{ Three years after operation } \\
\hline & $\begin{array}{l}\text { Excision } \\
\text { arthroplasty }\end{array}$ & $\begin{array}{l}\text { Metatarsal } \\
\text { osteotomy }\end{array}$ & $\begin{array}{l}\text { Excision } \\
\text { arthroplasty }\end{array}$ & $\begin{array}{l}\text { Metatarsal } \\
\text { osteotomy }\end{array}$ \\
\hline $\begin{array}{c}\text { Abnormal rotation present }(\%) \\
\text { Average rotation (degrees) } \\
\text { Average valgus (degrees) }\end{array}$ & $\begin{array}{l}50 \\
39 \\
45\end{array}$ & $\begin{array}{l}62 \\
40 \\
42\end{array}$ & $\begin{array}{l}61 \\
25\end{array}$ & $\begin{array}{l}33 \\
14\end{array}$ \\
\hline $\begin{array}{c}\text { Abnormal rotation absent }(\%) \\
\text { Average valgus (degrees) }\end{array}$ & $\begin{array}{l}50 \\
26\end{array}$ & $\begin{array}{l}38 \\
32\end{array}$ & $\begin{array}{l}39 \\
16\end{array}$ & $\begin{array}{l}67 \\
12\end{array}$ \\
\hline
\end{tabular}

Table $\mathbf{V}$. The association between the degree of valgus deformity and passive correction of the first metatarsophalangeal joint

\begin{tabular}{|c|c|c|c|c|}
\hline & \multicolumn{2}{|c|}{ Before operation } & \multicolumn{2}{|c|}{ Three years after operation } \\
\hline & $\begin{array}{l}\text { Excision } \\
\text { arthroplasty }\end{array}$ & $\begin{array}{l}\text { Metatarsal } \\
\text { osteotomy }\end{array}$ & $\begin{array}{l}\text { Excision } \\
\text { arthroplasty }\end{array}$ & $\begin{array}{l}\text { Metatarsal } \\
\text { osteotomy }\end{array}$ \\
\hline $\begin{array}{c}\text { Complete passive correction (\%) } \\
\text { Average valgus (degrees) }\end{array}$ & $\begin{array}{l}50 \\
29\end{array}$ & $\begin{array}{l}57 \\
34\end{array}$ & 14 & 9 \\
\hline $\begin{array}{l}\text { Partial passive correction (\%) } \\
\text { Average valgus (degrees) }\end{array}$ & $\begin{array}{l}50 \\
43\end{array}$ & $\begin{array}{l}43 \\
43\end{array}$ & 29 & 18 \\
\hline
\end{tabular}

The range of movement at the first metatarsophalangeal joint and the rotation of the hallux were assessed with the patient supine and the ankle plantigrade. The line of the lateral four toes viewed end-on from above was taken as the neutral axis and the degree of rotation of the nail of the great toe away from this axis was recorded. All measurements were made with a goniometer.

Standard anteroposterior and lateral radiographs of the foot were obtained with the patient in the standing weight-bearing position. Films were taken before operation, soon after operation (before discharge from hospi- tal) and on attending for review three years later. The degree of valgus at the first metatarsophalangeal joint, the first intermetatarsal angle and the length of the first metatarsal relative to the second were measured using the method described by Hardy and Clapham (1951). The presence of subluxation or osteoarthritis at the metatarsophalangeal joint was noted. Displacement of the sesamoids was assessed by measuring the distance of the lateral border of the medial sesamoid from the central longitudinal axis of the first metatarsal. Any proximal migration of the sesamoids was calculated by measuring the distance from the articular surface of the 
head of the first metatarsal, along its central longitudinal axis, to a point transected by a perpendicular passing through the distal pole of the medial sesamoid.

Twenty-three excision arthroplasties ( 7 bilateral) were performed on 16 patients and 26 distal metatarsal osteotomies (9 bilateral) performed on 17 patients. Of these 33 patients, 29 attended for review at least three years after operation. A comparison of the results of 20 excision arthroplasties and of 24 metatarsal osteotomies forms the basis of this paper. Analysis of the patients' pre-operative status revealed that the two groups were very similar (Tables I to V).

\section{Operative technique}

Keller's arthroplasty (Keller 1904) was performed through a straight dorsomedial incision. Reflection of the soft tissues enabled the medial exostosis to be removed flush with the shaft of the metatarsal. The proximal half of the proximal phalanx was exposed subperiosteally and excised. A Z-lengthening of the extensor hallucis longus tendon was performed if it was judged to be exerting a deforming force after phalangeal resection.
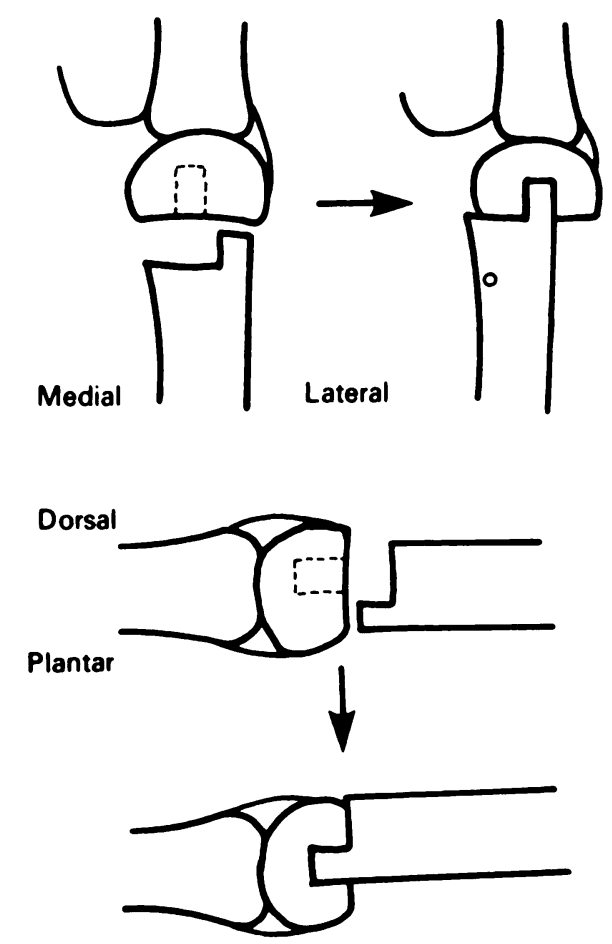

Fig. 1

Diagram showing the distal metatarsal osteotomy. Above, anteroposterior view; below, lateral view.

No attempt was made to preserve length or conserve joint space by use of a Kirschner wire or by other means. After closure of the wound, the toe was bandaged in slight plantarflexion and neutral adduction/abduction. Toe flexion exercises were encouraged in the immediate postoperative period and weight-bearing was begun on the day of operation. The patient was taught to stand on a wooden board $2 \mathrm{~cm}$ thick and to plantarflex the great toe actively over the edge. The sutures were removed at about 14 days after operation and an Elastoplast spica was applied to maintain a few degrees of plantarflexion and neutral alignment at the metatarsophalangeal joint; this spica was worn for four weeks.

The distal metatarsal osteotomy was a modification of the type devised by Thomasen (Mygind 1952). Through a curved dorsomedial incision the capsule and periosteum were incised in a $\mathrm{Y}$ fashion, based on the proximal phalanx. A transverse osteotomy through the cancellous bone at the base of the metatarsal head allowed greater lateral displacement of the distal fragment than if the osteotomy were made more proximally. A peg was fashioned on the lateral and plantar aspects of the proximal fragment and a reciprocal socket to receive this peg was excavated from the distal fragment (Fig. 1). This allowed the distal fragment to be displaced laterally and plantarwards, firm fixation being secured before wound closure. The resultant metatarsal shortening reduced the tension of the soft tissues on the lateral side of the joint. This enabled a VY-plasty of the capsuloperiosteal flap to overcome the valgus deformity and to maintain correction (Hawkins et al. 1945). A plaster forefoot cast which allowed weight-bearing was worn for between four and six weeks.

\section{RESULTS}

The success of the two methods of operative treatment in relieving patients' symptoms when assessed three years after operation was similar (Table VI). The range of movement of the first metatarsophalangeal joint was, however, better maintained after osteotomy (Tables III and VII).

The residual valgus angle at the first metatarsophalangeal joint, measured on a weight-bearing anteroposterior radiograph taken before discharge from hospital, averaged 4 in both groups. Comparable radiographs taken three years later showed that the osteotomised patients had a significantly smaller angle than those who had undergone arthroplasty, although the angle had increased in both groups (Table II). The problem is therefore a failure to maintain correction of the deformity after excision arthroplasty.

From the radiographs taken soon after the operation the extent of proximal phalangeal resection was calculated for those patients who underwent Keller's procedure. An average of $42 \%$ of the phalanx was removed $(1.2 \mathrm{~cm})$, yet at the time of review the measurable gap between the metatarsal head and the phalangeal remnant averaged only $0.2 \mathrm{~cm}$. This overall shortening of the first ray by $1.0 \mathrm{~cm}$ was greater than the $0.8 \mathrm{~cm}$ which occurred after osteotomy.

Lateral displacement of the medial sesamoid relative to the central longitudinal axis of the first metatarsal occurred pre-operatively in all the patients undergoing osteotomy and in $81 \%$ of those undergoing Keller's pro- 
Table VI. Subjective results, in percentages, three years after operation

\begin{tabular}{llc}
\hline & $\begin{array}{l}\text { Excision } \\
\text { arthroplasty }\end{array}$ & $\begin{array}{l}\text { Metatarsal } \\
\text { osteotomy }\end{array}$ \\
\hline Overall patient satisfaction & & \\
$\quad$ Complete & 75 & 79 \\
$\quad$ Partial & 15 & 13 \\
$\quad$ Dissatisfied & 10 & 8 \\
Complete pain relief & 70 & 75 \\
Cosmetic satisfaction & & \\
$\quad$ Complete & 70 & 75 \\
$\quad$ Partial & 20 & 25 \\
$\quad$ Dissatisfied & 10 & 0 \\
Function-unrestricted walking & 93 & 93 \\
\hline
\end{tabular}

Table VII. Percentage change in the range of movement at the first metatarsophalangeal joint before operation and three years later

\begin{tabular}{|c|c|c|c|}
\hline & Increased & Decreased & Unchanged \\
\hline $\begin{array}{l}\text { Active dorsiflexion } \\
\text { Excision arthroplasty } \\
\text { Metatarsal osteotomy }\end{array}$ & $\begin{array}{l}55 \\
89\end{array}$ & $\begin{array}{l}30 \\
11\end{array}$ & $\begin{array}{r}15 \\
0\end{array}$ \\
\hline $\begin{array}{l}\text { Passive dorsiflexion } \\
\text { Excision arthroplasty } \\
\text { Metatarsal osteotomy }\end{array}$ & $\begin{array}{l}30 \\
50\end{array}$ & $\begin{array}{l}40 \\
44\end{array}$ & $\begin{array}{r}30 \\
6\end{array}$ \\
\hline $\begin{array}{l}\text { Active plantarflexion } \\
\text { Excision arthroplasty } \\
\text { Metatarsal osteotomy }\end{array}$ & $\begin{array}{r}15 \\
6\end{array}$ & $\begin{array}{l}75 \\
50\end{array}$ & $\begin{array}{l}10 \\
44\end{array}$ \\
\hline $\begin{array}{l}\text { Passive plantarflexion } \\
\text { Excision arthroplasty } \\
\text { Metatarsal osteotomy }\end{array}$ & $\begin{array}{l}15 \\
22\end{array}$ & $\begin{array}{l}80 \\
67\end{array}$ & $\begin{array}{r}5 \\
11\end{array}$ \\
\hline
\end{tabular}

cedure, being on average $0.6 \mathrm{~cm}$ in each group. Excision arthroplasty had little effect on this displacement which was found on review to have persisted in the same $81 \%$ to a value of $0.4 \mathrm{~cm}$. Osteotomy, however, reduced the average lateral shift from $0.6 \mathrm{~cm}$ to $0.1 \mathrm{~cm}$ and in addition restored the alignment to neutral in $66 \%$ of the patients.

An average proximal migration of the sesamoids of $0.3 \mathrm{~cm}$ occurred in $86 \%$ of patients treated by resection arthroplasty, but this did not occur in any of the patients treated by osteotomy. Indeed $80 \%$ demonstrated a relative distal shift of $0.2 \mathrm{~cm}$ due to proximal shift of the metatarsal head.

The first intermetatarsal angle was virtually unaffected by excision arthroplasty, averaging 13 before operation and 12 on review. In the osteotomised patients it was reduced from a pre-operative value of 16 to one of 7 three years after operation.

Complications. There were four cases of superficial infection amongst the patients treated by Keller's procedure and one in the osteotomy group. All responded quickly to appropriate treatment and there were no cases of deep infection.

\section{DISCUSSION}

In their review of the results of basal osteotomy for the treatment of hallux valgus. Bonney and Macnab (1952) reported that a frequent cause of an unsatisfactory result was failure to maintain the corrected position achieved at operation. In considering the optimal site for more distal osteotomy, Mitchell found that such loss of alignment was less likely, and union quicker, if the osteotomy was performed through the cancellous bone at the base of the metatarsal head rather than through the compact bone more proximally (Mitchell et al. 1958). They also suggested, as did Miller (1974), that distal osteotomy in patients over the age of 55 was associated with an increased risk of delayed union and subsequent loss of correction. Carr and Boyd (1968) considered that the time to bony union represented a relative contra-indication to osteotomy in this age group. The need to fashion a large enough peg, and to be conservative in excavating the socket should be recognised, so that firm fixation is obtained under direct vision. In the present series $60 \%$ of the patients treated by osteotomy were aged more than 60 years at the time of operation, but there were no cases of delayed union or of non-union.

The only soft tissue structures related to the metatarsal head which are left undisturbed when performing the osteotomy are situated on the lateral aspect. Maintaining the integrity of these capsular attachments is vital in ensuring the vascularity of the distal fragment during the postoperative period before bony union (Mitchell $e t$ al. 1958; Carr and Boyd 1968). Avascular necrosis of the metatarsal head did not occur in any of our patients.

Opinions differ concerning the relationship between pain under the lateral four metatarsal heads on weightbearing, and the length of the first metatarsal relative to the second. Hawkins et al. (1945) thought that any relative first metatarsal shortening was likely to result in lateral metatarsalgia by causing lateral shift of load distribution, as described by Morton (1927). Harris and Beath (1949), however, observed that a relatively short first metatarsal was a common and apparently normal occurrence and not necessarily an aetiological factor in the causation of forefoot symptoms. In fact relative protrusion of the first metatarsal head was discovered by Hardy and Clapham (1951) to be commoner in patients with hallux valgus than in a normal control group. Mitchell et al. (1958) argued that operative shortening of the first metatarsal might be desirable and concluded that postoperative metatarsalgia affecting the second toes was related not to the amount by which shortening had occurred, but to insufficient plantar displacement or angulation of the distal fragment. Gibson and Piggott (1962) reported similar findings in their series, where dorsal angulation of the distal fragment was found to be responsible for the persistence or development of lateral metatarsalgia. Shortening of more than the average of $0.6 \mathrm{~cm}$ was not the cause of a poor result. Carr and Boyd (1968) found that metatarsalgia of the second toe arose in patients in whom more than $0.7 \mathrm{~cm}$ had been excised, although they did not specify the final amount of shortening which occurred. However, a review by Dooley (1968) of 17 patients treated by Wilson's method 
of oblique displacement osteotomy reported no metatarsalgia despite an average shortening of $1.0 \mathrm{~cm}$.

Lateral metatarsalgia commonly exists in conjunction with symptomatic hallux valgus. An investigation using footprint analyses by Henry and Waugh (1975) showed that the aetiology of pain on the plantar aspects of the middle metatarsal heads was related to increased loading at these sites, which could be secondary to diminished load-bearing by the pulp of the great toe. They further showed that the big toe bears weight in only $40 \%$ of cases after a Keller's procedure. Work by Hutton and Dhanendran (1979) revealed that in normal feet the great toe and the first metatarsal each transmit a load which is about twice the combined loads of the lateral four toes. Hallux valgus is associated with reduced loading of all the toes and increased loading of the metatarsal heads. After Keller's procedure the loading of the hallux is further reduced, that of the first metatarsal head is increased and that of the lateral metatarsal heads remains unchanged (Dhanendran et al. 1980). These findings lend support to Cleveland and Winant (1950) who observed that Keller's operation did not result in any symptomatic improvement of metatarsalgia affecting the second or third toes. Although Bonney and Macnab (1952) concluded that excision arthroplasty had an unpredictable effect on metatarsalgia, Miller (1974) considered that metatarsalgia in combination with hallux valgus represented an indication for osteotomy as opposed to arthroplasty.

All the patients treated by osteotomy in our series had a first metatarsal which was relatively longer than the second before the operation and relatively shorter after operation. Operative resection of $0.5 \mathrm{~cm}$ resulted in an average shortening on review of $0.8 \mathrm{~cm}$. In this group $29 \%$ of the patients had pre-operative metatarsalgia. Of the $21 \%$ in whom the first metatarsal head was affected, $17 \%$ were completely relieved of symptoms after operation, and $4 \%$ were improved. Lateral weight-bearing radiographs of the improved patients showed that there had been slight dorsal tilt of the distal fragment, insufficient to cause the development of lateral metatarsalgia. Of the $8 \%$ of patients with pre-operative lateral metatarsalgia, symptoms had totally resolved in $4 \%$ and improved in the other $4 \%$ at the time of review. In particular there were no new instances of lateral metatarsalgia developing for the first time. Our findings would seem to support the observation that a relatively short first metatarsal does not cause lateral metatarsalgia if, after osteotomy, the distal fragment is displaced plantarwards and maintained in this position until union occurs.

Metatarsalgia was present pre-operatively in $45 \%$ of the patients treated by Keller's excision arthroplasty in this series. Pain beneath the first metatarsal head, present in $25 \%$, disappeared in $20 \%$ and persisted postoperatively in only $5 \%$. Of the $20 \%$ with lateral metatarsalgia, complete relief was achieved in $10 \%$, but the other $10 \%$ were not improved. More significant was the fact that $20 \%$ of those who had previously been painfree developed lateral forefoot pain on weight-bearing. Thus $30 \%$ were found on review to have lateral metatarsalgia and in $80 \%$ of these the second metatarsal head was the site of the problem.

The majority of patients in both groups $(95 \%)$ complained at presentation of pain overlying the medial aspect of the first metatarsal head, but at review there were no cases of recurrent pain at this site. Forefoot narrowing after excision arthroplasty was due entirely to excision of the exostosis. Reduction in width after osteotomy, however, is greater because the operation reduces the first intermetatarsal angle. The normal first intermetatarsal angle in young adults has been found by several authors to be less than 10 (Hawkins et al. 1945; Hardy and Clapham 1951), but whether this applies to older adults without hallux valgus is not known. In our series the intermetatarsal angle was reduced from $16^{\circ}$ to 9 thus restoring it to below the upper limit of normal and helping to narrow the forefoot.

The eventual alignment of the first metatarsal after osteotomy, as seen on the anteroposterior radiograph, depends upon the extent to which the distal fragment is displaced laterally (Carr and Boyd 1968). The potential for this shift is greatest when the osteotomy is performed through the broad cancellous region at the base of the metatarsal head; so much so that after repositioning the distal fragment the dorsomedial corner of the proximal fragment is potentially protuberant and may require to be suitably trimmed.

One of the most striking features which became apparent on review was the frequency with which patients complained of symptoms affecting one or other of the lateral four toes. Flexion deformities, usually of the proximal interphalangeal joint of the second toe, had developed in $17 \%$ of the osteotomy and in $15 \%$ of the arthroplasty patients. The main complaint was of a painful callosity overlying the dorsal aspect of the affected joint, in association with a flexion deformity. It would therefore appear likely that shortening of the first ray, from whatever procedure, predisposes the patient to a significant risk of later developing deformities of the lateral four toes.

Although most patients had manifest subluxation and osteoarthritis of the first metatarsophalangeal joint before operation (Table II), a higher percentage of the osteotomy patients maintained a greater degree of movement after operation, especially dorsiflexion (Tables III and VII). The range of dorsiflexion has been reported to be functionally more important than the range of plantarflexion (Helal, Gupta and Gojaseni 1974). There is thus no evidence from these results to support the hypothesis that subluxation or osteoarthritis should be considered as contra-indications to a joint-conserving osteotomy.

The average degree of valgus correction in the 
patients who underwent osteotomy was from $38^{\circ}$ preoperatively to 12 three years later; this is significantly better than that achieved for the group which underwent arthroplasty, where the main problem was that the correction gained at operation was subsequently lost again.

We would like to thank Mr Denis Dunn who stimulated us to conduct this study, and the other surgeons at Black Notley Hospital who allowed us to treat their patients.

\section{REFERENCES}

Blunden RE. Hallux valgus in the adolescent. $J$ Bone Joint Surg $[\mathrm{Br}]$ 1968:50 B:677.

Bonney G, Macnab I. Hallux valgus and hallux rigidus: a critical survey of operative results. J Bone Joint Surg [Br] 1952:34 B:366-85.

Carr CR, Boyd BM. Correctional osteotomy for metatarsus primus varus and hallux valgus. J Bone Joint Surg $[\mathrm{Am}]$ 1968;50 A:1353 67.

Cholmeley JA. Hallux valgus in adolescents. Proc $R$ Soc Med 1958;51: 9036.

Cleveland M, Winant EM. An end-result study of the Keller operation. $J$ Bone Joint Surg $[\mathrm{Am}]$ 1950;32-A:163-75.

Dhanendran M, Pollard JP, Hutton WC. Mechanics of the hallux valgus foot and the effect of Keller's operation. Acta Orthop Scand 1980:51:1007 12 .

Dooley BJ. Osteotomy of the metatarsal neck for hallux valgus. $J$ Bone Joint Surg [Br] 1968:50- B:677.

Gibson J, Piggott H. Osteotomy of the neck of the first metatarsal in the treatment of hallux valgus: a follow-up study of eighty-two feet. J Bone Joint Surg [Br] 1962;44 B:349-55.
Glynn MK, Dunlop JB, FitzPatrick D. The Mitchell distal metatarsal osteotomy for hallux valgus. J Bone Joint Surg $[\mathrm{Br}]$ 1980;62 B: 188-91.

Hardy RH, Clapham JCR. Observations on hallux valgus: based on a controlled series. J Bone Joint Surg [Br] 1951:33-B:376 91.

Harris RI, Beath T. The short first metatarsal: its incidence and clinical significance. J Bone Joint Surg [Am] 1949;31 A:553 65.

Hawkins FB, Mitchell CL, Hedrick DW. Correction of hallux valgus by metatarsal osteotomy. J Bone Joint Surg 1945:27:387 94.

Helal B, Gupta SK, Gojaseni P. Surgery for adolescent hallux valgus. Acta Orthop Scand 1974:45:271 95

Henry APJ, Waugh W. The use of footprints in assessing the results of operations for hallux valgus: a comparison of Keller's operation and arthrodesis. J Bone Joint Surg [Br] 1975:57-B:478-81.

Hutton WC, Dhanendran M. A study of the distribution of load under the normal foot during walking. Int Orthop 1979:3:153 7.

Keller WL. The surgical treatment of bunions and hallux valgus. $\mathrm{Nr}$ Med J 1904:80:741-2.

Miller JW. Distal first metatarsal displacement osteotomy: its place in the schema of bunion surgery. J Bone Joint Surg [Am] 1974:56 A $923-31$.

Mitchell CL, Fleming JL, Allen R, Glenney C, Sanford GA. Osteotomybunionectomy for hallux valgus. J Bone Joint Surg $[\mathrm{Am}]$ 1958: 40 A: 4160 .

Morton DJ. Metatarsus atavicus: the identification of a distinctive type of foot disorder. J Bone Joint Surg 1927:9:531 44.

Mygind H. Operations for hallux valgus. J Bone Joint Surg [Br] 1952 : 34-B: 529 .

Piggott $\mathbf{H}$. The natural history of hallux valgus in adolescence and early adult life. J Bone Joint Surg [Br] 1960;42 B:749 60.

Wilson JN. Oblique displacement osteotomy for hallux valgus. $J$ Bone Joint Surg [Br] 1963:45 B:552 6. 